\title{
In memory of Professor Marcella Motta
}

\author{
P. Limonta ${ }^{1} \cdot$ R. C. Melcangi ${ }^{1}$
}

Received: 22 July 2019 / Accepted: 23 July 2019 / Published online: 2 August 2019

(C) Italian Society of Endocrinology (SIE) 2019

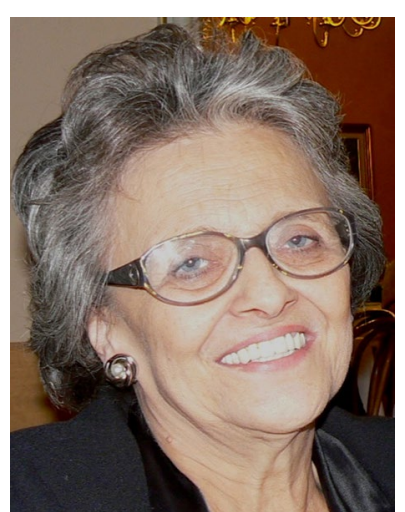

Marcella Motta, Full Professor of Physiology at the University of Milano died peacefully on June 27, 2019.

In 1968, she started her academic career as Assistant Professor of Pharmacology at the Department of Pharmacology of the University of Milano. She became Associate Professor of Endocrine Pharmacology at the University of Pavia in 1972 and then Associate Professor of Physiology at University of Milano in 1973. In 1980 she became Full Professor of Physiology at the same University.

At the University of Milano, she served from 1995 to 2002 as President of the Council of Professors of the Graduate Course of Pharmacy, from 2001 to 2004 as Director of the Postgraduate School in Experimental Endocrinology and from 2001 to 2007 as Chairman of the Department of Endocrinology.

Professor Motta's main research interests were neuroendocrinology, physiology of reproduction, metabolism of sex steroids, endocrine aspects of tumors. She started developing these interests by attending, as visiting scientist, the
Department of Neuroendocrinology-Maudsley Hospital in London (Director Prof. G-W. Harris) and the Worcester Foundation for Experimental Biology-Shrewsbury-USA (Director Prof. G. Pincus). Based on these experiences, she then gave a significant contribution to the understanding of the role exerted by steroid and peptide hormones in the field of endocrine-related cancers. The results of her research led to the improvement of the therapeutic strategies for these tumors and specifically for prostate cancer. Indeed, she contributed with more than 200 publications in the major scientific journals devoted to the field of endocrinology and cancer research. She was also editor of several proceedings and textbooks. In addition, Professor Marcella Motta was President of the Italian Society of Medical Andrology and Sexuology, Vice-President of the International Society of Neuroendocrinology, of the Italian Society of Endocrinology and of the Italian Society of Physiopathology of Reproduction.

Professor Motta was also one of the founders of the Italian Group of Neuroendocrine Sciences. The promoter Committee of this group included scientists with different expertise, such as neuroanatomy, neurophysiology, neurobiology, neuropharmacology, and psychoneuroendocrinology, with the aim to promote the development of basic and clinical research in the field of neuroendocrine sciences. In addition, and this was particularly promoted by Professor Motta, one of the most important actions of this group was to stimulate the interest of the young researchers for this discipline.

We will remember Professor Motta for her humor, brilliant intelligence and generosity.

We will miss you Professor Motta!

Her collaborators

R. C. Melcangi

roberto.melcangi@unimi.it

1 Dipartimento di Scienze Farmacologiche e Biomolecolari, Università degli Studi di Milano, Milan, Italy 